\title{
Agency and Communion From the Perspective of Self Versus Others
}

\author{
Andrea E. Abele \\ University of Erlangen-Nuremberg
}

\author{
Bogdan Wojciszke \\ Polish Academy of Sciences
}

\begin{abstract}
On the basis of previous research, the authors hypothesize that (a) person descriptive terms can be organized into the broad dimensions of agency and communion of which communion is the primary one; (b) the main distinction between these dimensions pertains to their profitability for the self (agency) vs. for other persons (communion); hence, agency is more desirable and important in the self-perspective, and communion is more desirable and important in the other-perspective; (c) self-other outcome dependency increases importance of another person's agency. Study 1 showed that a large number of trait names can be reduced to these broad dimensions, that communion comprises more item variance, and that agency is predicted by self-profitability and communion by other-profitability. Studies 2 and 3 showed that agency is more relevant and desired for self, and communion is more relevant and desired for others. Study 4 showed that agency is more important in a close friend than an unrelated peer, and this difference is completely mediated by the perceived outcome dependency.
\end{abstract}

Keywords: agency, communion, self versus others, interdependence

The aim of the present article was to show that the two basic dimensions for describing and judging persons and groups, called agency and communion, can be linked to a basic distinction in social information processing, namely, the perspective of self and the perspective of other people. We argue that agency is basically related to goal-pursuit of the self, and communion is basically related to consideration of others. Whereas communion is primary and relevant in every social relationship, agency, besides being important for the self, should be relevant for others as well if the self-other relationship is an interdependent one. Four studies lend support to this theorizing.

\section{Agency and Communion as Basic Dimensions for Judgments of Self, Others, and Groups}

In a recent article, Judd, James-Hawkins, Yzerbyt, and Kashima (2005; see also Fiske, Cuddy, \& Glick, 2006) argued that there is remarkable consensus about the fundamental dimensions underlying social judgments. These basic dimensions have different names and slightly different meanings, and they were studied in different research contexts like person perception, self research, personality, group perception, or values. However, they share common cores

Andrea E. Abele, Social Psychology Group, University of ErlangenNuremberg, Erlangen, Germany; Bogdan Wojciszke, Department of Psychology, Polish Academy of Sciences, Warsaw, Poland.

This research was supported by the German Alexander von Humboldt Foundation and the Polish Ministry of Science. We thank Wiesiek Baryla, Sabine Pahl, and the participants of the Erlangen Social Psychology Group for valuable discussions and comments on previous versions of this article. We also thank Elke Finger, Olga Kwiecinska, Agnieszka Sztuczynska, Stefanie Wening, and Jakub Wojcik for their help in data collection.

Correspondence concerning this article should be addressed to Andrea E. Abele, Social Psychology Group, University of Erlangen-Nuremberg, Bismarckstr. 6, D 91054, Erlangen, Germany. E-mail: abele@phil.unierlangen.de that the present work attempts to elucidate and analyze empirically.

Regarding judgments of others, the classic work of Asch (1946) revealed two basic dimensions in impression formation (see also Zanna \& Hamilton, 1972). Rosenberg, Nelson, and Vivekananthan (1968) used multidimensional scaling procedures for the similarity of trait terms used in describing persons. They also found a two-dimensional structure that they called intellectual versus social desirability (see also Rosenberg \& Sedlak, 1972). Wojciszke (2005) differentiated between competence and morality (cf. Reeder \& Brewer, 1979; Reeder, Pryor, \& Wojciszke, 1992), and Kinder and Sears (1985) claimed that moral integrity and competence constitute two separate and basic clusters of traits in the perception of political leaders (cf. Chemers, 2001; see also consideration vs. initiating structure; Halpin \& Winer, 1957).

Regarding judgments of self, there are also several similar conceptualizations of two basic dimensions. Bakan (1966) introduced the terms of agency versus communion and argued that these are "two fundamental modalities in the existence of living forms, agency for the existence of an organism as an individual and communion for the participation of the individual in some larger organism of which the individual is part" (pp. 14-15). Agency arises from strivings to individuate and expand the self and involves such qualities like instrumentality, ambition, dominance, competence, and efficiency in goal attainment. Communion arises from strivings to integrate the self in a larger social unit through caring for others and involves such qualities like focus on others and their well-being, cooperativeness, and emotional expressivity. Instrumentality versus expressiveness are terms developed by sociologists Parsons and Bales (1955), who observed that members of groups can be distinguished with respect to instrumental versus expressive functions they serve. Instrumental functions are oriented at good adaptation and optimal goal fulfillment of the group as part of a larger social system. Expressive functions are directed at coherence, solidarity, and harmony within the group. Another two-dimensional approach for self-description is independence 
versus interdependence. Following conceptualizations of cultures (Hofstede, 1980; Triandis, 1995), it was argued that individualistic versus collectivistic values and cultural priorities give rise to differentiation of personal identities-independent versus interdependent self-construal (Markus \& Kitayama, 1991; Sedikides, Gaertner, \& Toguchi, 2003; Triandis, 1995). Independent selfconstrual means defining the self in terms of unique qualities, whereas interdependent self-construal means defining the self in terms of relationships with others.

Regarding personality constructs, again, two basic dimensions can be distinguished. There is evidence that agency and communion are two independent superordinate factors of personality that broadly cover the dominance/ambition (agency) versus nurturance/ warmth (communion) dimensions of the interpersonal circumplex (Wiggins, 1991). Digman (1997) showed that the Big Five personality dimensions can be organized into two themes or superfactors, namely, personal growth (agency) and socialization (communion; see also Blackburn, Renwick, Donnelly, \& Logan, 2004; Saragovi, Aubé, Koestner, \& Zuroff, 2002). With respect to biases in self-perception, Paulhus and John (1998) distinguished an agency-related egoistic bias-the "superhero" bias-which is a tendency to exaggerate one's social and intellectual status and leads to positive self-perceptions on such traits as dominance, intellect, and creativity versus a communion-related moralistic bias-the "saint" bias_-being a tendency that leads to positive self-perceptions on such traits as agreeableness, dutifulness, and nurturance (see also Helgeson \& Fritz, 1998, 2000). Originating in Terman and Miles' (1936) research on gender differences in personality, psychological masculinity versus psychological femininity is another conceptualization that on the operational level by and large can be equated with agency versus communion.

Regarding group perception and stereotypes, gender stereotypes are expressed on two basic dimensions, with agency being related to the male stereotype and communion being related to the female one (Bem, 1974; Eagly, 1987; Spence, Helmreich, \& Stapp, 1974). Competence and morality are distinct dimensions of national and ethnic stereotypes that explain the perceived distances between national groups better than a purely evaluative one-dimensional ordering (Phalet \& Poppe, 1997). On the basis of similar ideas, Fiske and colleagues (Fiske, Cuddy, Glick, \& Xu, 2002) developed a general stereotype content model and showed that there are two basic and independent dimensions of stereotype content named warmth and competence (see also Fiske et al., 2006; Glick \& Fiske, 2001). The perception of groups as competent or incompetent follows from their high or low position in the status power hierarchy, whereas the perception of groups as warm or cold results from their benevolence or lack of intention to compete against the perceiver's own group.

In summary, there are similar two-dimensional conceptualizations of person attributes in social and personality psychology, which may be broadly subsumed under headings like agency and communion. The agency dimension relates to intellectual desirability, to competence, to initiating structure, to instrumentality, to the egoistic bias, to dominance, and to an independent selfconstrual. The communion dimension relates to social desirability, to morality, to consideration, to expressiveness, to the moralistic bias, to nurturance, and to an interdependent self-construal.

We choose the agency versus communion terms because they are common in different fields of social psychology like person perception, group perception, stereotypes, and self-description Furthermore, their usefulness has been demonstrated in other areas of psychology like autobiographical memory (McAdams, Hoffman, Mansfield, \& Day, 1996), psychological well-being (Helgeson, 1994), occupational development (Abele, 2003), attachment styles (Bartz \& Lydon, 2004), reward distribution behavior (Watts, Messé, \& Vallacher, 1982), or information processing (Woike, Lavezzary, \& Barsky, 2001). These terms are thus widely acknowledged, and they are conceptualized broadly enough to cover a number of related concepts.

\section{Agency and Communion in the Perspectives of Self and Others}

Thus far, our analysis supports the reasoning that there are two fundamental dimensions underlying social judgments. Whereas Judd et al. (2005) were concerned with how the two dimensions are related to each other and Fiske et al. (2002) were concerned with how they relate to stereotypes of different groups, we are concerned here with how they are related to the basic characteristics of social cognition and social interaction, namely, the distinction between self and others.

People perceive and evaluate themselves and others in a way that maximizes their own interests and current goals (Kunda, 1999). They are "acting selves" and "observing others." This acting-observing difference has consequences on social information processing, and the well-known actor-observer difference in attributions is a prominent example (Jones \& Nisbett, 1971; see also Fiske \& Taylor, 1991; Malle, 2006; Watson, 1982).

From an evolutionary or social functionalist perspective, people are interested in an effective pursuit of their goals and in benevolent relationships with others. We suggest that agency is the dimension primarily related to the interests of the self. As was already noted by Bakan (1966), agentic attributes cover strivings to individuate, expand the self, and efficiently attain one's goals. Agentic traits like being active, decisive, self-confident, and efficient are profitable and useful in the perspective of the self because they help to attain one's goals. Communion, conversely, is the dimension primarily related to the interests of others. Referring to Bakan (1966), communal attributes cover strivings to integrate the self in a larger social unit through caring for others. Regarding the perspective of an observing "other," the actor should respect the interests of this observing other and should be benevolent, trustworthy, friendly, and empathetic. A core distinction between agentic versus communal traits hence seems to be their self-profitability versus other-profitability.

This reasoning was inspired by research on the evaluative meaning of traits, in which the concepts of self-profitability and otherprofitability were introduced (Peeters, 1992, 2005; Peeters, Cornelissen, \& Pandelaere, 2006). According to these authors, the evaluative meaning of traits reflects their adaptive value for humans in general. This adaptive value can be defined from the perspective of the self (i.e., the trait possessor), and traits adaptive to the self have been called self-profitable. Self-profitable traits are qualities that are directly and unconditionally profitable (in the case of positive traits) or harmful (in the case of negative ones) for the trait possessor. Other people may also benefit from selfprofitable traits, but this depends on the trait possessor's goals and intentions. In our reasoning, these are agentic traits. A trait's 
adaptive value can, however, also be defined from the perspective of another person who observes the trait possessor. Traits adaptive in the perspective of another person have been called otherprofitable. Other-profitable traits are directly beneficial for other people when positive and directly harmful for them when negative.

The idea that agency is a dimension related to the interests of the self, whereas communion is a dimension related to the interests of other people, is suggested by Asch's (1946) classical finding that "warm" versus "cold" are central traits in impression formation (i.e., in the observer perspective). Findings on the stereotype content model (Fiske et al., 2002) also fit our reasoning: Stereotyping of groups as warm or cold (i.e., communal traits), is dependent on their benevolence in relation to the perceiver's own group (i.e., on the interests of the observer). Stereotyping of groups as competent versus incompetent (i.e., agentic traits) follows from their high or low position in the status-power hierarchy (i.e., is dependent on the more or less efficient pursuit of self-interests of the respective group). Findings on gender stereotypes can also be integrated into our framework. The agentic male stereotype is connected with roles that foster the interests of the self, whereas the communal female stereotype is connected with roles that foster other-interest (Conway, Pizzamiglio, \& Mount, 1996; Diekman \& Eagly, 2000; Eagly \& Karau, 2002). Findings of Abele and colleagues (Abele, 2003; Abele, Rupprecht, \& Wojciszke, in press) on changes and variations in self-ascribed agency and communion can be interpreted in a similar way. These authors found that agency increases if self-interests (success at a task; success in one's occupational career) are fulfilled. Communion is a predictor of involvement in social relations and interests of others.

Things are more complicated, however. Agency as the dimension of self-profitable attributes may, under certain conditions, also be a dimension of other-profitable attributes. If, for instance, a person is efficient in the pursuit of goals that are desirable not only for the self but also for other persons, then his or her agency is both self-profitable and profitable for the other person. Consequently, other-profitability is a stable characteristic of communal traits but a variable characteristic of agentic traits. Agentic traits can be socially useful; they do not have to be so, however. This idea of potential social utility of agentic traits was also suggested by Peeters (1992, 2005), who argued that other people may benefit from self-profitable traits, but this depends on the trait possessor's goals and intentions (see also Beauvois \& Dubois, 2000; Peeters et al., 2006). This idea is also implicit in the above-mentioned instrumentality versus expressiveness approach (Parsons \& Bales, 1955), in which the differentiation of instrumentality (agency) and expressiveness (communion) does not pertain to individual traits but rather to group functions people serve.

The dual nature of agency as being self-profitable and under certain conditions also being other-profitable and socially useful is conceivable in terms of the specific relationship between self and other. Considering friends, acquaintances, partners, children, advisors, subordinates, relatives, and the like, it is self-evident that the nature of the relationship between self and others varies with who the other is. These relations vary in the degree of interdependence between self and other, or, stated differently, the degree to which the self is outcome dependent on the other. At one extreme, self and other are more or less independent, and the degree of goal attainment of the acting self may be irrelevant for the other. In this case, the "other" would be an unconcerned "observer." Take as an example two persons who see each other regularly because they attend the same classes but have no joint activities. At the other extreme, self and other may be highly interdependent, and the degree of goal attainment of the self may be highly relevant for the other (i.e., he or she is outcome dependent). As examples, one could think of a married couple or of two persons working together as supervisor and subordinate. Interdependence and outcome dependency have been shown to influence attributions (Berscheid, Graziano, Monson, \& Dermer, 1976; Fiske, 2000; Thibaut \& Kelley, 1959) and to influence evaluations (Vonk, 1999a, 1999b). We argue that they also influence the other-profitability of agentic traits. If the other person is an unconcerned "observer," then he or she should mainly be interested in the actor's communion. If, however, the other person is a concerned "recipient," then he or she should be interested in the actor's communion as well as agency.

Another question to be posed here is related to the relative importance of agency and communion within one perspective, that is, within the perspective of the self or the perspective of the other. On the basis of many findings in the area of impression formation (cf. Asch, 1946; Rosenberg et al., 1968; Rosenberg \& Sedlak, 1975) and based on evolutionary reasoning on the importance of close relationships (cf. Fiske et al., 2006), we assume that in both the perspective of the self and the perspective of others communion is primary. Communion is the most important dimension because close and secure relationships that include friendliness, trust, empathy, and helpfulness are indispensable for survival. This does not preclude that agentic traits are highly desired and important from the perspective of the self, and also from the perspective of an interdependent other. The importance of agency, however, is assumed to be more variable in dependence on perspective (self vs. other) and in dependence on the kind of relationship (independence, dependence, interdependence).

\section{The Present Research}

Our general hypotheses are as follows: (a) Person descriptive terms can be organized into two broad dimensions of agency and communion, in which communion is the primary one. (b) Agency being self-profitable is more related to the perspective of the self, and communion being other-profitable is more related to the perspective of others. (c) The more there is interdependence between the self and the other, the more agency becomes otherprofitable and socially useful.

We tested Hypotheses 1 and 2 in a correlational design in Study 1. Three hundred trait words were rated for agency/communion, morality/competence, individualism/collectivism, and masculinity/ femininity. We predicted a two-factorial structure of these ratings, with one factor comprising the agency dimension (agency, individualism, masculinity, and competence) and the other the communion dimension (communion, collectivism, femininity, morality). The communion dimension should cover more item variance than the agency dimension. The traits were also rated for the degree they serve the interests of the self versus others. We assumed that the agency dimension would be predicted by selfinterest, and the communion dimension would be predicted by other-interest.

Studies 2 and 3 aimed at experimentally testing predictions derived from Hypothesis 2. In Study 2, participants recalled im- 
portant autobiographical events from the perspective of the self versus another person. We predicted that events remembered from the perspective of the self are more agentic in content, whereas events remembered from the perspective of another person are more communal in content. In Study 3, we assumed that if agentic content is more profitable for the self and communal content is more profitable for others, then if having the choice to decide which of two skills training to attend, participants would prefer agentic skills training for themselves but communal skills training for others.

In Study 4, we tested predictions derived from Hypothesis 1 and especially Hypothesis 3. Participants rated the importance of agentic and communal traits for themselves and for one of two others, either an unrelated peer or a close friend. We predicted that communion would be rated as more important than agency, that agency would be rated as more important for the self than for others, and that agency would be rated as more important for the close friend than for the unrelated peer. We further tested our assumption that the differential importance of agentic traits for different others is mediated by perceived outcome dependency.

\section{Study 1}

A pool of 300 trait names was rated to the degree they expressed competence versus morality, individualism versus collectivism, agency versus communion, and masculinity versus femininity. Following Hypothesis 1, we predicted that a factor analysis of these ratings would reveal two independent dimensions. One dimension should comprise the ratings of agency, individualism, masculinity, and competence, and the other dimension should comprise the ratings of communion, collectivism, femininity, and morality. The communion factor should have a higher eigenvalue than the agency factor. All traits were rated for the extent they served interests of self versus interests of others in both a shorttime and a long-time perspective. We included time perspective for exploratory reasons. Following Hypothesis 2, the agency dimension should be positively correlated with the interests of self but not with the interests of others. Communion should be positively correlated with the interests of others and, to a smaller degree, with the interests of self as well. Finally, the traits were also rated for favorability because descriptive and evaluative meanings are related (Peabody, 1967).

\section{Method}

Participants. Participants were 320 Polish university students (age range $=19-40$ years, $M=22.53,198$ women) who received a list of 300 personality trait names. Every participant rated them by random assignment for only one of the criteria explained below. The trait names were given in an alphabetical, ascending or descending order. Participants took the rating sheets home and brought them back a few days later.

Traits. A pool of 300 trait names was selected to be representative for all dimensions described in the introduction (see also Anderson, 1968; Goldberg, 1992). More specifically, we included traits considered most typical for agency or communion (Bakan, 1966; Helgeson, 1994). We also borrowed stereotypically feminine and masculine traits from Bem (1974) and Spence et al. (1974), traits most typical for the intellectually good-bad and socially good-bad dimensions (Rosenberg et al., 1968), traits considered to be self-profitable or other-profitable (Peeters, 1992; Wentura, Rothermund, \& Bak, 2000), morality- or competencerelated traits (Wojciszke, 1994, 2005), traits expressing warmth or competence (Fiske et al., 2002), and individualistic or collectivistic traits (Sedikides et al., 2003). Additionally, 60 traits identifying the Big Five factors were included (borrowed from a Polish list of Big Five markers; Szarota, 1995).

Ratings. Eighty participants rated the traits' global favorability on a scale from -5 (very negative) to 0 (neutral) to 5 (very positive). Twelve groups of participants (always 20 persons) rated the traits on one of the following criteria: agency, communion, masculinity, femininity, individualism, collectivism, competence, morality, short-time self-interest, short-time other-interest, longtime self-interest, and long-time other-interest. Participants responded using 11-point rating scales, presented graphically and accompanied by an extended instruction. For example, the instruction for "communion" read:

Please rate each of the 300 traits for the degree the trait is communal or noncommunal. Communion means an orientation to people, focus on interpersonal contacts and relationships, striving for being included into a community, and for remaining a member of this community Please use a scale ranging from -5 (very noncommunal) to 0 (neutral) to 5 (very communal).

Detailed instructions for how to use the scale followed with examples of one communal and one noncommunal trait, in this case "helpful" and "irritable." The instruction for "long-time selfinterest" was as follows:

Please rate each of the 300 traits for the degree the trait is beneficial or harmful for a person showing this trait. We want you to consider only long-time benefits or losses which are different from short-time benefits or losses, i.e., those emerging immediately after the behavior expressing a trait. Please use a scale ranging from -5 (very harmful for the trait possessor in the long run) to 0 (neutral) to 5 (very beneficial to the trait possessor in the long run).

Detailed instructions for how to use the scale followed with examples of a harmful and a beneficial trait, in this case, "dumb" and "tenacious."

\section{Results}

Preliminary analyses. We first computed the internal consistencies of the 20 ratings per criterion as well as the 80 traits' favorability ratings. The mean interrater correlation of the favorability ratings was $.80(p<.001)$. The interrater agreement was even higher for the specific content dimensions and interests, with all $r s \geq .92(p<.001)$. We therefore used the averaged ratings of each trait in the further analyses.

Whereas the descriptive meanings (agency, communion, masculinity, femininity, individualism, collectivism, competence, and morality) of the 300 traits were normally distributed, the distribution of evaluative meanings (global favorability, short-time selfand other-interests, long-time self- and other-interest) were bi-

\footnotetext{
${ }^{1}$ The precise wording of all instructions is available from Bogdan Wojciszke upon request.
} 
modal and significantly different from normality $(p s<.001$, Kolmogorov-Smirnov test). Because of this bimodality, the analyses reported below were performed for all traits as well as separately for negative traits (125 items that were below zero on global favorability) and positive traits (175 items that were above zero on global favorability).

Factorial structure. Ratings of the eight content dimensions were subjected to a principal component analysis, yielding a clear two-factorial solution as suggested consistently by scree plots, eigenvalues, and the amount of variance explained by the factors. These two factors explained $89 \%$ of the variance. Table 1 shows the factor loadings after varimax rotation. The first factor comprises two thirds of the item variance $(66.19 \%)$, and it is characterized by communal content. The second factor $(23.2 \%$ of the item variance) comprises the agentic content. This structure also emerged when the analyses were performed separately for positive and negative traits and when they were performed for a random subsample of the items, suggesting the robustness of the findings. ${ }^{2}$

Agency and communion as related to self-interest versus otherinterest. We computed scales for the agency dimension (masculinity, independence, competence, agency; Cronbach's $\alpha=.90$ ) and for the communion dimension (femininity, interdependence, morality, communion; Cronbach's $\alpha=.87$ ) by averaging the respective ratings. We also averaged the short-time and long-time interest ratings for self $(r=.93)$ and for others $(r=.98)$ because they were nearly identical. We then computed the correlations between the agency and communion scales and the interest ratings. Because there had been clearly positive versus clearly negative traits, we computed the correlations separately for negative versus positive traits.

Supporting our predictions, self-interest was positively correlated, and other-interest was not correlated with agency (see Table 2 ). The findings are the same for both negative and positive traits. Also supporting our predictions, communion was positively correlated with other-interest and, to a smaller degree, with selfinterest. Again, the same pattern emerged for negative and positive traits.

\section{Discussion}

Hypothesis 1 was supported by these findings: A large number of trait terms can be reduced to the basic dimensions of agency and

Table 1

Factor Loadings of Content Dimensions for the 300 Trait

Names

\begin{tabular}{lrr}
\hline \multicolumn{1}{c}{ Variable } & Factor 1 & Factor 2 \\
\hline Eigenvalue & 5.30 & 1.86 \\
Percentage of item variance & 66.19 & 23.20 \\
Loadings & .94 & .26 \\
$\quad$ Communion & .95 & .11 \\
Collectivism & .89 & .25 \\
Morality & .84 & .28 \\
Femininity & .12 & .96 \\
Agency & .12 & .93 \\
Individualism & .40 & .89 \\
Competence & .39 & .86 \\
Masculinity & & \\
\hline
\end{tabular}

Table 2

Correlations Between Interests of Self Versus Others and the Agency and Communion Scales in Study 1

\begin{tabular}{lcccc}
\hline \multicolumn{1}{c}{ Variable } & 1 & 2 & 3 & 4 \\
\hline 1. Agency scale & - & -.03 & $.67^{* * * *}$ & .12 \\
2. Communion scale & -.06 & - & $.49^{* * *}$ & $.89^{* * * *}$ \\
3. Self-interest & $.69^{* * *}$ & $.24^{* *}$ & - & $.69^{* * * *}$ \\
4. Other-interest & -.12 & $.82^{* * *}$ & $.24^{* * *}$ & - \\
\hline
\end{tabular}

Note. $n=125$ negative and $n=175$ positive trait words. Positive traits appear above the diagonal; negative traits appear below the diagonal. ${ }^{*} p<.01 .{ }^{* * * *} p<.001$.

communion. Agency is the common core of dimensions like individualism, competence and intellectual functioning, and stereotypic masculinity. Communion is the common core of dimensions like collectivism, morality and social functioning, as well as stereotypic femininity. Supporting the assumption of the primacy of communion, this factor comprised more item variance than the agency factor. Supporting Hypothesis 2, the two dimensions are differently related to the interests of self versus other. Agency is positively related to self-interest and not related to other-interest. Communion is positively related to other-interest and, to a smaller degree, to self-interest. In summary, our hypotheses were supported with respect to the dimensionality of the trait names, the primacy of communion, and the relatedness of agency to selfprofitability and of communion to other-profitability.

\section{Study 2}

Study 1 showed that agentic and communal traits are differentially related to self- versus other-interest. In Study 2, we tested whether reports of events that had been important enough to influence self-esteem are also differently related to agency versus communion in dependence on whether the event is reported from the perspective of self versus the perspective of another person. Important events reported from the perspective of self should be more agentic in content, and important events reported from the perspective of another person should be more communal in content. The demonstration of such a difference would support Hypothesis 2 with another operationalization than the one chosen in Study 1.

We asked Study 2 participants to recall and describe in detail an event that had influenced the actor's self-evaluation in a positive or a negative way. They had to describe both an event they had experienced themselves (perspective of self) and an event another person (perspective of other) had experienced. These event descriptions were later rated for the extent they expressed agentic versus communal content by independent judges who were blind to the experimental hypotheses. We predicted an interaction between perspective (self vs. other) and content (agentic vs. communal): Events reported from the perspective of self should allude

\footnotetext{
${ }^{2}$ We also selected a $50 \%$ random sample of the 300 trait terms and computed the same principal component analysis in order to test the robustness of the findings. It resulted in an almost identical solution (two factors, first factor communal content with $65.97 \%$ of item variance; second factor agentic content with $23.62 \%$ of item variance).
} 
to agency rather than to communion, and events reported from the perspective of another person should allude to communion rather than to agency. We also expected that the events would be rated higher on agency if reported from the perspective of the self and that they would be rated higher on communion if reported from the perspective of another person.

\section{Method}

Participants and design. Sixty-one Polish university students (27 men and 34 women) participated in small groups of three to five persons. The design was a 2 (self- vs. other-perspective) $\times 2$ (event: increasing vs. decreasing evaluation) $\times 2$ (gender) analysis of variance (ANOVA), with repeated measures on the first factor.

Procedure and manipulation. Participants were asked to describe "an event after which you got to think of yourself in a better (worse) way than before." There were two questions on the answering sheet: (a) "What was the event, what did you do?" and (b) "Why did you think better (worse) of yourself afterward?" After having completed the event description, the participants had to rate how much they had experienced a number of different emotions during this event. Participants were also asked to describe an event from the perspective of another person (a peer of the same gender, not the closest friend) and to answer the same questions as above from the perspective of the other person. The order of describing an event from the perspective of the self or another person was balanced and had no effect on the results, as shown by preliminary analyses.

Dependent measures. Event content was rated by four independent raters blind to the hypotheses. Two raters rated the event descriptions for agentic content, and two other raters rated them for communal content. The instruction for the agency rating was "To what extent does this event show that the acting person is agentically oriented, that is, he or she is oriented toward doing things in an efficient way or that he or she is not oriented to action and its efficiency?" Communion relatedness was defined as "an orientation toward other people, focus on relationships and contacts with others" (vs. lack of it). The answers were given on 11-point scales ranging from -5 (no agency, communion [respectively]) to 0 (hard to say) to 5 (high agency, communion [respectively]). The raters' responses were averaged because they showed a high level of agreement $(r \mathrm{~s}>.70)$. The ratings of positive and negative actions mirrored each other (showing the same patterns), and in order to facilitate data presentation and discussion, the ratings were converted to absolute values. The agency and communion scores hence describe the extent to which the event was related to agency/ communion or lack of it. Sample events rated as high in agency and low in communion are "I passed a driver's license test at the first attempt. Many people fail at their first attempt, so I was very proud of myself", "A teaching assistant scored my essay as very poor. I felt pretty down." Sample events high in communion but low in agency are "A friend of mine helped his neighbor's kid in math. I was impressed because he wouldn't take any money from the neighbor", "A fellow student refused to lend me her notes from a lecture that I missed."

Manipulation check. In order to check whether the remembered events were comparable in terms of experienced emotions, both with respect to event valence (positive vs. negative) and to perspective (self vs. other), participants had to rate the extent to which a number of emotions had been experienced during this event (gratitude, happiness, satisfaction, anger, apathy, depression, disappointment, guilt, shame) on scales ranging from 1 (not at all) to 7 (very much). We used the mean ratings of positive and negative emotions in the further analyses.

\section{Results and Discussion}

Manipulation check. A 2 (perspective: self vs. other) $\times 2$ (event: increasing vs. decreasing evaluation) $\times 2$ (gender) $\times 2$ (emotion valence) repeated measures ANOVA on the first and last factor was performed. A highly significant interaction of event type and emotion valence was the only effect in this analysis, $F(1$, $58)=430.74, p<.001, \eta^{2}=.82$. Events increasing evaluations led to much stronger positive $(M=4.68)$ than negative $(M=1.47)$ emotions, and events decreasing evaluations led to much stronger negative $(M=3.50)$ than positive $(M=1.33)$ ones. More important, there was no higher order interaction involving the perspective factor, $F(1,58)=1.14, p=.44$, and the main effect of perspective was also not significant, $F(1,58)=1.19, p=.28$. We conclude that the manipulation was successful. Participants reported more positive emotions if having been asked to remember events increasing evaluation, and they reported more negative emotions if having been asked to remember events decreasing evaluation. The self- versus other-perspective did not matter. Therefore, the perspective differences reported below cannot be attributed to differences in emotional experiencing between remembered events involving the self versus others.

Content of events. The event content ratings were subjected to a 2 (perspective: self vs. other) $\times 2$ (event valence: increasing vs. decreasing evaluation) $\times 2$ (rating: agency vs. communion) $\times 2$ (participant's gender) ANOVA, with repeated measures on the first and third factor. The predicted interaction between perspective and content was highly significant, $F(1,57)=16.75, p<$ $.001, \eta^{2}=.23$. As can be seen in Figure 1, events reported from the perspective of the self were rated higher on agency than on communion, $t(60)=3.76, p<.001$, and events reported from the perspective of another person were rated higher on communion than on agency, $t(60)=2.72, p<.01$. Moreover, the agentic content was more pronounced in the self-perspective, $t(60)=2.71$,
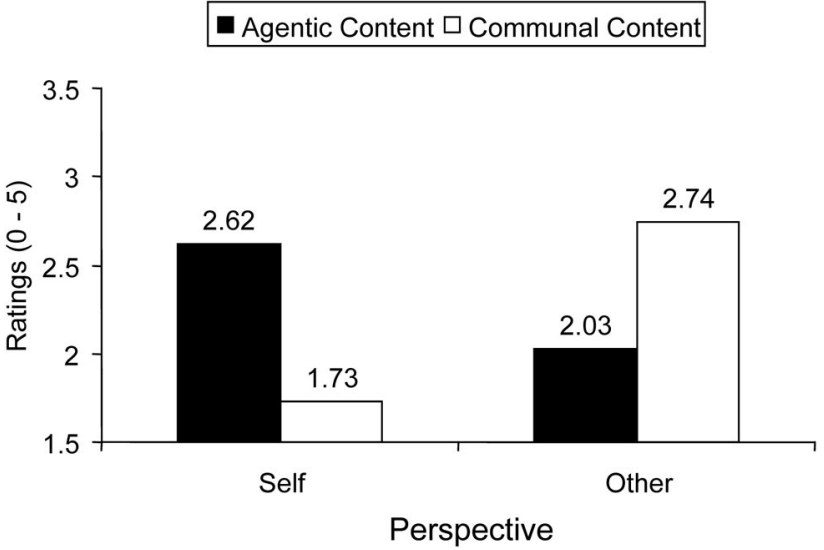

Figure 1. Content ratings of event descriptions reported from the perspective of the self versus another person in Study 2. 
$p<.01$, whereas the communal content was more pronounced in the other-perspective, $t(60)=3.81, p<.001$. There was no three-way Perspective $\times$ Content $\times$ Valence interaction $(F<1)$, meaning that the pattern shown in Figure 1 holds for both negative (evaluation-decreasing) and positive (evaluation-increasing) events. There were also no gender effects relevant for our hypotheses. $^{3}$

The results are in line with our predictions. Important events reported from the perspective of self were rated as containing more agentic than communal content. Important events reported from the perspective of another person were rated as containing more communal than agentic content. These findings support our general reasoning that agency and communion are differently related to the perspective of the self versus another person.

\section{Study 3}

Supporting Hypothesis 2, we have shown that agentic versus communal content is differently related to self-interest versus other-interest (see Study 1) and that events reported from the perspective of the self are more agentic in content, whereas events reported from the perspective of another person are more communal in content (see Study 2). Study 3 aims at further testing predictions derived from Hypothesis 2: If agency is more relevant for the self, and communion is more relevant for another person, then agentic skills should be more desirable from the perspective of the self, and communal skills should be more desirable from the perspective of another person.

We presented our participants with descriptions of psychological training that focused on the improvement of either agentic or communal skills. We asked them either how much they would like to participate in each of these trainings or how much they would like another person to participate in these trainings. We predicted an interaction between perspective and training type. Training for agentic skills should be preferred for the self, and training for communal skills should be preferred for another person.

\section{Method}

Participants and design. Participants were 62 Polish college students (19 men and 43 women; age range $=19-24$ years; $M=$ $19.71, S D=1.15)$. The design was a 2 (perspective: self vs. other) $\times 2$ (training type: agentic vs. communal) $\times 2$ (gender) ANOVA, with repeated measures on the second factor.

Procedure, manipulation, and measures. Participants received descriptions of four trainings written in the style of a commercial advertisement. The descriptions were always one-page long and contained identical information on duration $(30 \mathrm{hr})$, on the advertising institution (a fictitious training center called PROFIS), and on costs. The descriptions only differed with respect to the focus of the trainings. Two trainings ("Giving Social Support" and "Moral Self-Development") pertained to communal skills, and two others pertained to agentic skills ("Time Management" and "Persuading an Audience"). Thirty-one participants rated how much they would like to participate (self-perspective) in each of the trainings on a scale ranging from 1 (not at all) to 7 (very much). Another 31 participants rated how much they would like another person (a specific peer of the same sex, not a close friend) to participate in each of the trainings (other-perspective). The aver- aged ratings for the two agentic skills trainings and the two communal skills trainings served as dependent measures.

\section{Results}

Ratings of willingness to participate were subjected to a 2 (perspective: self vs. other) $\times 2$ (training: agentic vs. communal skills) $\times 2$ (participant's gender) factorial ANOVA, with repeated measures on the second factor. This analysis yielded two relevant effects. First, there was a main effect of training type, $F(1,58)=$ $19.35, p<.001, \eta^{2}=.25$. Agentic skills trainings $(M=5.03)$ were generally preferred over communal skills trainings $(M=$ 3.92). Second, the predicted interaction of Perspective $\times$ Training Type emerged, $F(1,58)=12.77, p<.001, \eta^{2}=.18$. As can be seen in Figure 2, agentic skills trainings were more preferred for the self than for another person, $t(60)=2.04, p<.05$, and communal skills trainings were more preferred for another person than for the self, $t(60)=3.20, p<.01 .^{4}$

\section{Discussion}

Hypothesis 2 was again supported. Agency is not only more relevant (see Studies 1 and 2) but also more desired (see Study 3) in the perspective of the self than in the perspective of another person. Communion is both more relevant and more desired in the perspective of another person than in the perspective of the self. The data further showed an unpredicted main effect of training type, with agentic trainings being generally preferred over communal ones. It may be that our participants thought that a training of agentic skills is generally more useful to students than one of communal skills. This finding, however, has no influence on the supporting evidence we found for Hypothesis 2.

\section{Study 4}

Study 4 was designed to test Hypothesis 3. Dependent on the specific other person being looked at, profitability and social utility of this other person's agentic traits for the self should vary, and hence the ascribed importance of these traits should vary as well.

To test this prediction, we asked the Study 4 participants to rate the importance of a number of agentic and communal traits both with respect to the self and to either an unrelated other (a fellow student) or an interrelated other (a close friend). Following Hypotheses 1 and 3 , we predicted that agentic traits would be rated as

\footnotetext{
${ }^{3}$ There was no main effect of participants' gender $(F<1)$, but we found a significant interaction between gender and content ratings, $F(1,57)=$ $4.72, p=.034, \eta^{2}=.08$. Events reported by women were rated as higher on communion $(M=2.86)$ than on agency $(M=2.29), F(1,31)=5.09$, $p=.031, \eta^{2}=.14$. Events reported by men did not differ in both ratings (agency $M=2.62$, communion $M=2.36 ; F<1$ ). However, there was no interaction with perspective $(F<1)$, and hence this finding is not relevant for the hypothesis testing.

${ }^{4}$ The third effect was a Gender $\times$ Training Type interaction, $F(1,58)=$ 4.99, $p<.03, \eta^{2}=.08$ : The preference for agentic over communal skills trainings was more pronounced for men (5.44 vs. 3.78), $t(18)=4.42, p<$ .001 , than for women $(4.61$ vs. 4.07$), t(42)=1.52, p<.14$. There was, however, no three-way interaction of gender, training type, and perspective $(F<1)$. Hence, the Gender $\times$ Training Type interaction is not relevant for our hypothesis testing.
} 


\section{- Agentic Training $\square$ Communal Training}

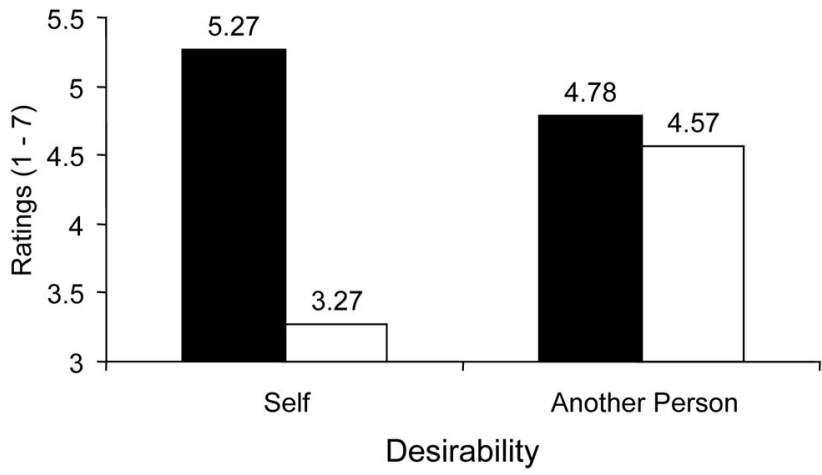

Figure 2. Desirability of agentic and communal trainings from the perspective of the self versus another person in Study 3.

more important for the self than for others; regarding the specific other, agentic traits should be rated as more important for a close friend than for an unrelated fellow student. Communal traits should be rated as generally more important than agentic ones. We also predicted that communal traits should be rated as more important in the case of a close friend than in the case of a fellow student.

Hypothesis 3 predicts that the differential importance of others' agentic traits is mediated by the degree of interdependence or outcome dependency of self and other. In order to test this assumption, we measured perceived outcome dependency. The different importance of agentic traits for a close friend versus for a fellow student should be mediated by this variable.

\section{Method}

Participants were 62 students from a German university (age range $=21-47 ; M=25.16, S D=5.12 ; 43$ women and 19 men) who filled out the questionnaire at the end of regular classes. They had to rate the importance of a number of traits (six communal: helpful, understanding, reliable, likable, empathetic, friendly; six agentic: competent, active, dynamic, efficient, assertive, selfconfident) on 5-point scales ranging from 1 (not important) to 5 (very important) for two targets, the self and another person. Reliability analyses showed that both the agency and the communion items formed internally consistent scales (agency $\alpha=.63$; communion $\alpha=.72$ ). We used averaged ratings as dependent measures. Dependent on condition, the participant had to imagine that the other person was either a fellow student with whom he or she had only little contact (unrelated other) or a close friend with whom he or she had many joint activities (related other). The design involved a 2 (comparison target: fellow student, close friend) $\times 2$ (ratings for self vs. other) $\times 2$ (ratings of agentic vs. communal traits) ANOVA, with repeated measures on the second and third factor and with balanced order of presentation. Half the participants first answered the questions related to the self; the other half first answered the questions related to the other person. Preliminary analyses showed that order of answering had no effect.

Participants also had to answer two questions on outcome dependency, "How much do you feel being influenced by the be- havior of this person?" and "How relevant is it for yourself that this other person reaches his/her goals?" on 5-point scales each ranging from 1 (not important) to 5 (very important).

\section{Results}

Manipulation check. We first analyzed how the two comparison targets were rated on the variables measuring outcome dependency. Participants felt more influenced by the behavior of a close friend $(M=3.70)$ than by the behavior of a fellow student $(M=2.38), t(60)=6.36, p<.001$. They also thought that the other person's goal attainment would be more important for themselves in the case of a close friend $(M=3.76)$ than in the case of a fellow student $(M=2.28), t(60)=7.14, p<.001$. Both ratings were significantly correlated $(r=.50, p<.001)$, and we averaged them in the analyses of mediation presented below.

Hypothesis testing. We computed a repeated measures ANOVA, with gender and comparison target (fellow student vs. close friend) as between-participants factors and importance ratings of agentic traits for self versus other as a repeated measures factor. This analysis revealed no gender main effects and interactions $(F \mathrm{~s}<1)$ but a highly significant repeated measures effect, $F(1,58)=184.18, p<.001, \eta^{2}=.76$, and the predicted Repeated Measures $\times$ Comparison Target interaction, $F(1,58)=4.28, p<$ $.05, \eta^{2}=.07$. As can be seen in Figure 3, participants rated agentic traits as more important for the self than for another person $(M=$ 4.15 vs. $M=2.94), t(61)=14.26, p<.001$, and they rated agentic traits as more important for a close friend $(M=3.09)$ than for a fellow student $(M=2.68), t(60)=2.85, p<.01$.

We then computed a repeated measures ANOVA for the importance ratings of communal traits. This analysis revealed no gender effects, $F \mathrm{~s}(1,58)<1.53, p<.23$; no repeated measures effect, $F(1,58)=1.74, p<.20, \eta^{2}=.03$; but a marginal interaction of the repeated measures factor with the comparison target, $F(1,58)=3.03, p<.09, \eta^{2}=.05$. There was no difference in the communal traits means if self and close friend had been rated (self $M=4.38$, close friend $M=4.33 ; t<1$ ). The communal traits ratings for a fellow student, however, were lower $(M=4.13)$ than those for the self, $t(28)=2.11, p<.05$, and they were also lower than those for a close friend, $t(60)=2.80, p<.01$.

\section{- Agentic Traits $\square$ Communal Traits}

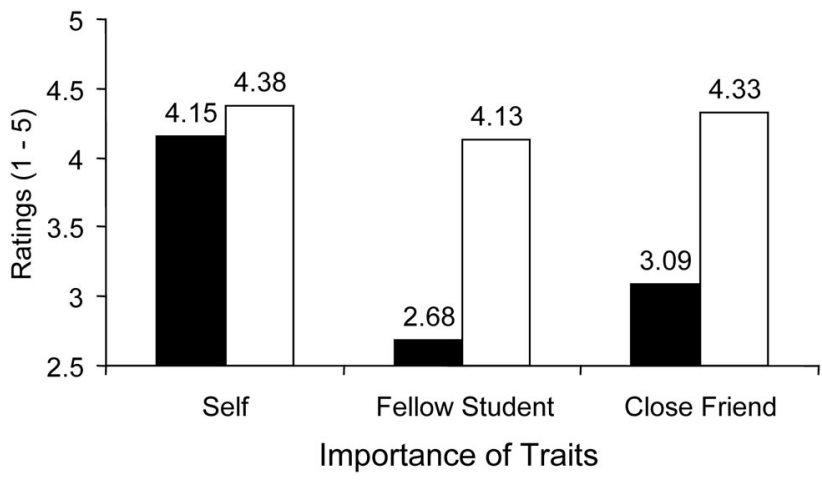

Figure 3. Importance of agentic and communal traits for the self versus for a fellow student versus for a close friend in Study 4. 
Relative importance of agency versus communion. Regarding others, communal traits were rated as much more important than agentic ones (communal traits $M=4.29$, agentic traits $M=2.94$ ), $F(1,61)=324.68, p<.001, \eta^{2}=.84$. The same finding resulted with respect to the self. The difference, however, was considerably weaker (communal traits $M=4.38$, agentic traits $M=4.15), F(1$, $61)=6.53, p<.02, \eta^{2}=.10$.

Analysis of mediation. We predicted that the higher importance of agentic traits in the case of a close friend compared with a fellow student is due to the higher outcome dependency in the case of a close friend. We performed a mediational analysis, with comparison other coded as the independent dummy variable $(0=$ fellow student; $1=$ close friend), agentic traits importance ratings as the dependent variable, and the mean outcome dependency rating as the mediator. As can be seen in the upper part of Figure 4 , the results fulfilled the mediation criteria (Baron \& Kenny, 1986). The unmediated effect (zero-order effect) of comparison target on the agency importance ratings was highly significant, and the influence of comparison target on outcome dependency was even stronger. When comparison target and interdependence rating were entered as simultaneous predictors of agency importance, outcome dependency significantly predicted the agency importance rating, but the mediated effect of comparison target dropped
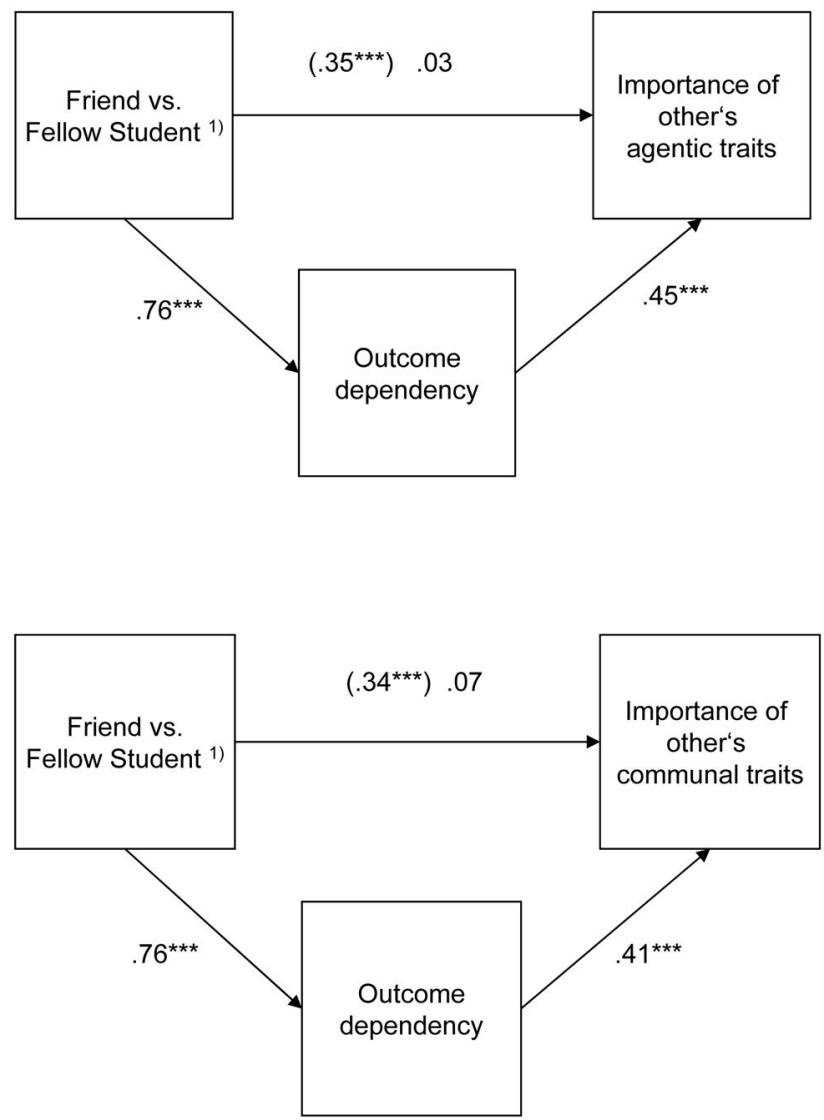

Figure 4. Importance of others' agentic and communal traits mediated by perceived outcome dependency in Study 4. Superscript 1 indicates that friend was dummy coded as 1 , and fellow student was dummy coded as 0 . ${ }^{* * * *} p<.001$. to a nonsignificant value $(\beta=.03, n s)$. This drop was significant, as evidenced by a Sobel test $(z=2.21, p<.05)$.

The mediation analysis for the others' communion ratings can be seen in the lower panel of Figure 4. The correlations also fulfilled the mediation criteria: Again, the unmediated effect of the comparison target on the communion ratings was significant, but the mediated effect of comparison target dropped to $\beta=.07$, if outcome dependency was simultaneously entered as a predictor. The Sobel test, however, did not reach a conventional level of significance $(z=1.64, n s)$.

\section{Discussion}

In support of Hypothesis 1, Study 4 showed that communion was generally rated as more important than agency. Also supporting Hypothesis 1, this effect was much larger for others than for the self. Supporting Hypothesis 2, Study 4 showed that agentic traits are rated as more important from the perspective of the self than that of another person. Most relevant, Study 4 showed that the comparison other matters. In support of Hypothesis 3, we found that agentic traits were rated as more important for a close friend than for a fellow student. This effect was mediated by perceived outcome dependency. The more participants thought that behavior and goal attainment of the other influenced them, the higher they rated the importance of this person's agentic traits.

There were only minor differences in importance ratings of communal traits, with lower ratings for a fellow student than for a close friend and for the self. These small differences reflect the generally high importance of communal traits. The mediational analysis showed that the impact of the comparison other on the importance of communal traits was also correlated with perceived outcome dependency, but the drop in explained variance, including the mediator, was smaller than in the case of agency, and the respective Sobel test failed to reach a conventional significance level.

\section{General Discussion}

As discussed in the introduction, there is a long tradition in social and personality psychology to distinguish fundamental dimensions for the description of persons and groups: social and intellectual desirability, individualism and collectivism, independent and interdependent self, competence and morality, competence and warmth, dominance and nurturance, masculinity and femininity, and so on. Following Bakan (1966), we call these fundamental dimensions agency and communion. Agency is related to strivings to individuate and expand the self and involves such qualities like instrumentality, ambition, dominance, competence, independence, stereotypical masculinity, and efficiency in goal attainment. Communion arises from strivings to integrate the self in a larger social unit through caring for others and involves such qualities like focus on others and their well-being, cooperativeness, expressivity, warmth, trustworthiness, interdependence, nurturance, and interdependence.

The present work builds on previous research analyzing parallels between these conceptualizations (Fiske et al., 2006; Judd et al., 2005) and extends it by showing that there is a substantial overlap of numerous of these distinctions (see Study 1), that communion is primary (see Studies 1 and 4), that agency and 
communion are differently related to interests of self and others (see Study 1) as well as to relevance and desirability for self and others (see Studies 2-4), and that the importance of agency in the perspective of another person varies as a function of who the other is in terms of interdependence (see Study 4).

Most important, we also offered a theoretical framework that enabled the prediction and explanation of these findings. We linked the fundamental dimensions of agency and communion to a basic distinction in social cognition and social interaction, namely, the distinction between the self and other people. As a core distinction between the fundamental dimensions of agency and communion, we argued that the former is more related to the interests of the self, whereas the latter is more related to the interests of others. Furthermore, we argued that communion is primary because in an evolutionary and social functionalist perspective, close and benevolent relationships-hence communal ones-are indispensable for survival of individuals and groups. Agency being very important for the self is differently important with respect to other people. If these other people have an influence on one's own well-being and goal pursuit, then these others' agentic traits are important as well. When there is no or only little outcome dependency between self and the other person, it is mainly the other's communal traits that count.

\section{Agency and Communion}

Study 1 showed that a large number of trait terms can be reduced to the dimensions of communion and agency proposed in the present study. The factor-analytic findings were very clear, and they were also robust as an analysis of a random sample of traits revealed. The two-factorial structure was also robust with respect to the evaluative meaning of the trait terms because both the analysis of negative traits and the analysis of positive ones showed the same results. As had been predicted, the communion factor comprised more item variance than the agency factor.

This finding adds to already existing research showing similar relations between several concept pairs studied in a more fragmented way. Wojciszke (1997), for instance, asked his participants to rate individualistic and collectivistic values for their competence- and morality-relatedness and found that individualistic values (e.g., "ambitious" and "capable") were more strongly related to competence than morality, whereas collectivistic values (e.g., "forgiving" and "honest") were more strongly related to morality than to competence. The author also found that participants primed with individualistic values construed ambiguous actions in agentic rather than communal terms, whereas participants primed with collectivistic values construed the same actions in terms of communion rather than agency. In a similar vein, Gardner, Gabriel, and Lee (1999) found that participants primed with independence endorsed individualistic values, whereas persons primed with interdependence endorsed collectivistic values to a higher extent. Similarly, Kemmelmeier (2003) showed that participants primed with an independent self opposed policies expressing collectivistic values (affirmative action) to a higher degree than participants primed with an interdependent self.

This distinction between communion and agency does not only add to researchers' understanding of the fundamental dimensions of social judgment, but it is also important with respect to reasoning about these different kinds of content. The idea that content matters was pioneered by Reeder $(1985,2006)$, who showed that attributions for ability or intelligence (in our terms, agency) follow different rules compared with attributions for morality or honesty (in our terms, communion). Reeder's ideas were echoed in impression formation research. When discrepant (both positive and negative) information about a person has to be integrated into an overall impression, it results in a positive impression in the agentic domain but in a negative impression in the communal domain (Skowronski \& Carlston, 1987; Wojciszke, Brycz, \& Borkenau, 1993). Studies on interpersonal attitudes are also relevant here: Although such attitudes are usually conceptualized as unitary phenomena, they may also be distinguished into liking and respect (e.g., Jamieson, Lydon, \& Zanna, 1987; Kiesler \& Goldberg, 1968). Because liking strongly depends on whether the attitude target is friendly and benevolent (information on communal traits), it may be predicted that liking depends more on the target's communal rather than agentic traits. Respect, however, is strongly related to social status, which is acquired by agentic individuals. Hence, the target's agentic traits should be more important for respect ratings. Accordingly, a series of studies showed that the difference between liking and respect for a target person was predicted by the relative amount of communal versus agentic trait information (Wojciszke, Abele, \& Baryla, 2007).

\section{The Self-Other Distinction}

We argued that one core distinction between agency and communion is their differential relatedness to the interests of the self versus the interests of others. This reasoning was inspired by research on the evaluative meaning of traits in which the concept of self-profitability versus other-profitability was introduced (Peeters, 1992, 2005; Peeters et al., 2006). Traits adaptive to the trait possessor (i.e., the self) are self-profitable, and traits adaptive to others who deal with the trait possessor are other-profitable. Agency as the dimension related to self-confidence and to efficient goal attainment serves more the interests of the self than the interests of others. Communion as the dimension related to caring, benevolence, and friendliness serves more the interests of others than the interests of the self.

This reasoning was supported in all studies in the present research. Study 1 showed that the communion dimension was highly correlated with other-interest, whereas the agency dimension was highly correlated with self-interest. The finding that the communion dimension was, to a smaller degree, also correlated with self-interest supports our reasoning that communion is indispensable in social functioning. Study 2 showed that important events are reported in agentic terms if considered from the perspective of the self and are reported in communal terms if considered from the perspective of another person. Study 3 showed that people prefer agentic training for themselves and communal training for others. Study 4 showed that agency is rated as more important for the self than for others.

Previous findings on agency predicting self-interest goals (career success, Abele, 2003; Kirchmeyer, 2002) and on communion predicting interest in social relationships but not in career progression (Abele, 2003; see also Judge, Higgins, Thoresen, \& Barrick, 1999, for agreeableness; Wojciszke, 1997, for individualistic vs. collectivistic values) are in line with this reasoning. 


\section{Different Others}

Our third prediction tested in the present series of studies was that the specific other matters. We argued that other-profitability is an inherent quality of communal traits. Friendliness, benevolence, or hostility (i.e., communal traits) are always useful (in the case of positive traits) or harmful (in the case of negative ones) for others dealing with the trait possessor. Other-profitability, however, is not an inherent quality of agentic traits. Being self-confident or decisive, for instance, is only then useful for another person dealing with the trait possessor if this other person is interdependent with him or her and/or is outcome dependent on him or her. Whether an agentic trait is other-profitable or not depends on the kind of relationship between self and other. The more there is interdependence and/or outcome dependency, the more should the trait possessor's agentic traits be other-profitable in the case of positive ones and other-harmful in the case of negative ones. This reasoning was inspired by Parsons and Bales' (1955) functionalist approach as well as the social utility considerations by Peeters and colleagues (Peeters, 1992, 2005; Peeters et al., 2006).

Supporting these assumptions, Study 4 showed that the importance of another person's agentic traits was in fact dependent on the specific "other." Agentic traits were rated as less important in the case of a fellow student than in the case of a close friend. Perceived outcome dependency was the factor mediating these findings. The ratings for the importance of another person's communal traits were much less variable and were also less mediated by perceived outcome dependency (see Study 4).

Findings from a recent study by Cottrell, Neuberg, and Li (2007) fit well into our theoretical framework. These authors analyzed the importance of different traits for different kinds of targets (generalized "ideal person"; "ideal persons" with respect to different social relationships; persons differently interrelated with the judging person). They hypothesized and found that traits like trustworthiness and cooperativeness are generally highly valued, whereas characteristics like intelligence are differently valued across tasks, goals, and functions. They derived the rationale for their studies from a sociofunctional analysis according to which humans are obligatory, interdependent, and hence are in need of trustworthy and cooperative relationships. In dependence on the specific functions they serve with others, people should select these others on the basis of traits needed for these functions. In our theorizing, trustworthiness and cooperativeness are important communal traits, and Cottrell et al.'s (2007) findings are in line with our assumption and findings that communion is otherprofitable and hence desired in others. In our theorizing, intelligence may be subsumed under agentic traits, and these authors' findings that intelligence only counts in certain relationships is in line with our reasoning that agentic traits are other-profitable and hence desired if there is outcome dependency between the self and the other person. Cottrell et al. (2007) did not aggregate their trait terms into fundamental dimensions, and they also did not compare the perspectives of self versus others. Their findings, derived from another theoretical approach, however, fit well with those of the present study.

\section{Conclusion}

To conclude, the present theorizing and data suggest that many bidimensional concepts in social and personality psychology can be subsumed under the basic dimensions of agency versus communion and that these basic dimensions are systematically linked to the perspective of self (trait possessor) versus other (dealing with the trait possessor). There are several venues of future research conceivable from this theorizing. First, it seems promising to do more research into the self-other relationship, and the desirability of traits in dependence on the specific other should be observed. If, for instance, an employee's salary is independent of his or her supervisor's management skills, then he or she might want the supervisor to be mainly communal. However, if the employee's salary is dependent on the supervisor's management skills, then the employee might want him or her to be agentic. Our theoretical framework allows a parsimonious integration of different traits into the underlying dimensions. Second, it seems promising to do more research on the time perspective of selfprofitability versus other-profitability. It may well be that traits that are mainly other-profitable in a short-time perspective become self-profitable in a longer time perspective. Third, research on the trait implications of observed behaviors in dependence on the specific other seems promising as well. Possibly, these trait implications are not only evaluatively different in dependence on the specific person observed but also differently related to the agency and communion dimension. Finally, the relationship between selfconstrual and trait desirability in self and others deserves research.

\section{References}

Abele, A. E. (2003). The dynamics of masculine-agentic and femininecommunal traits: Findings from a prospective study. Journal of Personality and Social Psychology, 85, 768-776.

Abele, A. E., Rupprecht, T., \& Wojciszke, B. (in press). The influence of success and failure on the agentic self-concept. European Journal of Social Psychology.

Anderson, N. H. (1968). Likableness ratings of 555 personality-trait words. Journal of Personality and Social Psychology, 9, 272-279.

Asch, S. E. (1946). Forming impressions of personality. Journal of $A b-$ normal and Social Psychology, 41, 259-290.

Bakan, D. (1966). The duality of human existence. Reading, PA: AddisonWesley.

Baron, R., \& Kenny, D. (1986). The moderator-mediator variable distinction in social psychological research: Conceptual, strategic, and statistical considerations. Journal of Personality and Social Psychology, 51, $1173-1182$

Bartz, J., \& Lydon, J. (2004). Close relationships and the working selfconcept: Implicit and explicit effects of priming attachment on agency and communion. Personality and Social Psychology Bulletin, 30, 13891401.

Beauvois, J.-L., \& Dubois, N. (2000). Affordances in social judgment: Experimental proof of why it is a mistake to ignore how others behave towards a target and look solely at how the target behaves. Swiss Journal of Psychology, 59, 16-33.

Bem, S. L. (1974). The measurement of psychological androgyny. Journal of Clinical and Consulting Psychology, 42, 155-162.

Berscheid, E., Graziano, W., Monson, T., \& Dermer, M. (1976). Outcome dependency: Attention, attribution, and attraction. Journal of Personality and Social Psychology, 34, 978-989.

Blackburn, R., Renwick, S. J. D., Donnelly, J. P., \& Logan, C. (2004). Big Five or Big Two? Superordinate factors in the NEO Five Factor Inventory and the Antisocial Personality Questionnaire. Personality and Individual Differences, 37, 957-970.

Chemers, M. M. (2001). Leadership effectiveness: An integrative review. In M. A. Hogg \& R. S. Tindale (Eds.), Blackwell handbook of social 
psychology: Group processes (pp. 376-399). Oxford, England: Blackwell Publishers.

Conway, M., Pizzamiglio, M. T., \& Mount, L. (1996). Status, communality, and agency: Implications for stereotypes of gender and other groups. Journal of Personality and Social Psychology, 71, 25-38.

Cottrell, C., Neuberg, S., \& Li, N. (2007). What do people desire in others? A sociofunctional perspective on the importance of different valued characteristics. Journal of Personality and Social Psychology, 92, 208231.

Diekman, A. B., \& Eagly, A. H. (2000). Stereotypes as dynamic constructs: Women and men of the past, the present and the future. Personality and Social Psychology Bulletin, 26, 1171-1188.

Digman, J. M. (1997). Higher-order factors of the Big Five. Journal of Personality and Social Psychology, 73, 1246-1256.

Eagly, A. H. (1987). Sex differences in social behavior: A social-role interpretation. Hillsdale, NJ: Erlbaum.

Eagly, A. H., \& Karau, S. J. (2002). Role congruity theory of prejudice toward female leaders. Psychological Review, 109, 573-598.

Fiske, S. (2000). Interdependence and the reduction of prejudice. In S. Oskamp (Ed.), Reducing prejudice and discrimination (pp. 115-135). Mahwah, NJ: Erlbaum.

Fiske, S. T., Cuddy, A., \& Glick, P. (2006). Universal dimensions of social cognition: Warmth and competence. Trends in Cognitive Sciences, 11, $77-83$.

Fiske, S. T., Cuddy, A. J., Glick, P., \& Xu, J. (2002). A model of (often mixed) stereotype content: Competence and warmth respectively follow from the perceived status and competition. Journal of Personality and Social Psychology, 82, 878-902.

Fiske, S. T., \& Taylor, S. E. (1991). Social cognition (2nd ed.). New York: McGraw-Hill.

Gardner, W. L., Gabriel, S., \& Lee, A. Y. (1999). "I" value freedom, but "we" value relationships: Self-construal priming mirrors cultural differences in judgment. Psychological Science, 10, 321-326.

Glick, P., \& Fiske, S. T. (2001). Ambivalent stereotypes as legitimizing ideologies: Differentiating paternalistic from envious prejudice. In J. Jost \& B. Major (Eds.), The psychology of legitimacy (pp. 278-306). Cambridge, England: Cambridge University Press.

Goldberg, L. R. (1992). The development of markers of the Big-Five factor structure. Psychological Assessment, 4, 26-42.

Halpin, A. W., \& Winer, B. J. (1957). A factorial study of the leader behavior descriptions. In R. M. Stogdill \& A. E. Coons (Eds.), Leader behavior: Its description and measurement (pp. 39-51). Columbus, $\mathrm{OH}$ : Bureau of Business Research.

Helgeson, V. S. (1994). Relation of agency and communion to well-being: Evidence and potential explanations. Psychological Bulletin, 116, 412428 .

Helgeson, V. S., \& Fritz, H. L. (1998). A theory of unmitigated communion. Personality and Social Psychology Review, 2, 173-183.

Helgeson, V. S., \& Fritz, H. L. (2000). The implications of unmitigated agency and unmitigated communion for domains of problem behavior. Journal of Personality, 68, 1031-1057.

Hofstede, G. (1980). Culture's consequences. Beverly Hills, CA: Sage.

Jamieson, D., Lydon, J., \& Zanna, M. P. (1987). Attitude and activity preference similarity: Differential bases of interpersonal attraction for low and high self-monitors. Journal of Personality and Social Psychology, 53, 1052-1060.

Jones, E. E., \& Nisbett, R. E. (1971). The actor and the observer: Divergent perceptions of the causes of behavior. Morristown, NJ: General Learning Press.

Judd, C., James-Hawkins, L., Yzerbyt, V., \& Kashima, Y. (2005). Fundamental dimensions of social judgment: Understanding the relations between judgments of competence and warmth. Journal of Personality and Social Psychology, 89, 899-913.

Judge, T. A., Higgins, C. A., Thoresen, C. J., \& Barrick, M. R. (1999). The big five personality traits, general mental ability, and career success across the life span. Personnel Psychology, 52, 621-652.

Kemmelmeier, M. (2003). Individualism and attitudes toward affirmative action: Evidence from priming experiments. Basic and Applied Social Psychology, 25, 111-119.

Kiesler, C., \& Goldberg, G. (1968). Multidimensional approach to the experimental study of interpersonal attraction: Effect of a blunder on the attractiveness of a competent other. Psychological Reports, 22, 693-705.

Kinder, D. R., \& Sears, D. O. (1985). Public opinion and political action. In G. Lindzey \& E. Aronson (Eds.), Handbook of social psychology (3rd ed., Vol. 2, pp. 659-741). New York: Random House.

Kirchmeyer, C. (2002). Change and stability in managers' gender roles. Journal of Applied Psychology, 87, 929-939.

Kunda, Z. (1999). Social cognition: Making sense of people. Cambridge, MA: MIT Press.

Malle, B. (2006). The actor-observer asymmetry in attribution: A (surprising) meta-analysis. Psychological Bulletin, 132, 895-919.

Markus, H. R., \& Kitayama, S. (1991). Culture and the self: Implications for cognition, emotion, and motivation. Psychological Review, 98, 224 253

McAdams, D. P., Hoffman, B. K., Mansfield, E. D., \& Day, R. (1996). Themes of agency and communion in significant autobiographical scenes. Journal of Personality, 64, 339-377.

Parsons, T., \& Bales, R. (1955). Family, socialization, and interaction processes. Glencoe, Scotland: Free Press.

Paulhus, D. L., \& John, O. P. (1998). Egoistic and moralistic biases in self-perception: The interplay of self-deceptive styles with basic traits and motives. Journal of Personality, 66, 1025-1060.

Peabody, D. (1967). Trait inferences: Evaluative and descriptive aspects. Journal of Personality and Social Psychology Monograph, 7, (Whole No. 644).

Peeters, G. (1992). Evaluative meanings of adjectives in vitro and in context: Some theoretical implications and practical consequences of positive negative asymmetry and behavioral-adaptive concepts of evaluation. Psychologia Belgica, 32, 211-231.

Peeters, G. (2005, July 19-23). Good and bad for self and other: Evaluative meaning processes in social cognition. Paper presented at the 14th general meeting of the European Association of Experimental Social Psychology, Würzburg, Germany.

Peeters, G., Cornelissen, I., \& Pandelaere, M. (2006). Approach-avoidance values of target-directed behaviours elicited by target-traits: The role of evaluative trait dimensions. Retrieved February 7, 2007, from http:// cpl.revues.org/document396.html

Phalet, K., \& Poppe, E. (1997). Competence and morality dimensions of national and ethnic stereotypes: A study in six eastern-European countries. European Journal of Social Psychology, 27, 703-723.

Reeder, G. D. (1985). Implicit relations between dispositions and behaviors: Effects on dispositional attribution. In J. H. Harvey \& G. Weary (Eds.), Attribution: Basic issues and applications (pp. 87-116). New York: Academic Press.

Reeder, G. D. (2006). From trait-behavior relations to perceived motives: An evolving view of positivity and negativity effects in person perception. Polish Psychological Bulletin, 37, 191-202.

Reeder, G. D., \& Brewer, M. B. (1979). A schematic model of dispositional attribution in interpersonal perception. Psychological Review, 86, $61-79$.

Reeder, G. D., Pryor, J. B., \& Wojciszke, B. (1992). Trait-behaviour relations in social information processing. In G. Semin \& K. Fiedler (Eds.) Language and social cognition (pp. 37-57). Beverly Hills, CA: Sage.

Rosenberg, S., Nelson, C., \& Vivekananthan, P. (1968). A multidimensional approach to the structure of personality impressions. Journal of Personality and Social Psychology, 9, 283-294.

Rosenberg, S., \& Sedlak, A. (1972). Structural representations of implicit 
personality theory. Advances in Experimental Social Psychology, 6, 235-297.

Saragovi, C., Aubé, J., Koestner, R., \& Zuroff, D. (2002). Traits, motives, and depressive styles as reflections of agency and communion. Personality and Social Psychology Bulletin, 28, 563-577.

Sedikides, C., Gaertner, L., \& Toguchi, Y. (2003). Pancultural selfenhancement. Journal of Personality and Social Psychology, 84, 60-79.

Skowronski, J. J., \& Carlston, D. E. (1987). Social judgment and social memory: The role of cue diagnosticity in negativity, positivity, and extremity biases. Journal of Personality and Social Psychology, 52, 689-699.

Spence, J. T., Helmreich, R. L., \& Stapp, J. (1974). The Personal Attributes Questionnaire: A measure of sex-role stereotypes and masculinity and femininity. Journal Supplement Abstract Service: Catalog of Selected Documents in Psychology, 4, 43-44.

Szarota, P. (1995). Polska Lista Przymiotnikowa (PLP): Narzedzie do diagnozy pieciu wielkich czynnikow osobowosci [Polish adjective list for measuring Big Five factors of personality]. Studia Psychologiczne, 33, 227-255.

Terman, L. M., \& Miles, C. C. (1936). Sex and personality. New York: McGraw-Hill.

Thibaut, J. W., \& Kelley, H. H. (1959). The social psychology of groups. New York: Wiley.

Triandis, H. C. (1995). Individualism and collectivism. Boulder, CO: Westview Press.

Vonk, R. (1999a). Differential evaluations of likeable and dislikeable behaviours enacted towards superiors and subordinates. European Journal of Social Psychology, 29, 139-146.

Vonk, R. (1999b). Effects of other-profitability and self-profitability on evaluative judgements of behaviours. European Journal of Social Psychology, 29, 833-842.

Watson, D. (1982). The actor and the observer: How are their perceptions of causality divergent? Psychological Bulletin, 92, 682-700.

Watts, B. L., Messé, L. A., \& Vallacher, R. R. (1982). Toward understand- ing sex differences in pay allocation: Agency, communion, and reward distribution behavior. Sex Roles, 8, 1175-1187.

Wentura, D., Rothermund, K., \& Bak, P. (2000). Automatic vigilance: The attention-grabbing power of approach- and avoidance-related social information. Journal of Personality and Social Psychology, 78, 10241037.

Wiggins, J. S. (1991). Agency and communion as conceptual coordinates for the understanding and measurement of interpersonal behavior. In W. Grove \& D. Ciccetti (Eds.), Thinking clearly about psychology: Essays in honor of Paul Everett Meehl (pp. 89-113). Minneapolis: University of Minnesota Press.

Woike, B., Lavezzary, E., \& Barsky, J. (2001). The influence of implicit motives on memory processes. Journal of Personality and Social Psychology, 81, 935-945.

Wojciszke, B. (1994). Multiple meanings of behavior: Construing actions in terms of competence and morality. Journal of Personality and Social Psychology, 67, 222-232.

Wojciszke, B. (1997). Parallels between competence- versus moralityrelated traits and individualistic versus collectivistic values. European Journal of Social Psychology, 27, 245-256.

Wojciszke, B. (2005). Morality and competence in person- and selfperception. European Review of Social Psychology, 16, 155-188.

Wojciszke, B., Abele, A. E., \& Baryla, W. (2007). Two dimensions of interpersonal attitudes: Liking depends on communion, respect depends on agency. Manuscript submitted for publication.

Wojciszke, B., Brycz, H., \& Borkenau, P. (1993). Effects of information content and evaluative extremity on positivity and negativity biases. Journal of Personality and Social Psychology, 64, 327-336.

Zanna, M. P., \& Hamilton, D. L. (1972). Attribute dimensions and patterns of trait inferences. Psychonomic Science, 27, 353-354.

Received May 15, 2006

Revision received May 29, 2007

Accepted June 14, 2007

\section{E-Mail Notification of Your Latest Issue Online!}

Would you like to know when the next issue of your favorite APA journal will be available online? This service is now available to you. Sign up at http://notify.apa.org/ and you will be notified by e-mail when issues of interest to you become available! 